\title{
INVENTORES DO BRASIL: UMA REVISITA AOS CLÁSSICOS
}

\author{
CARDOSO, Fernando Henrique. \\ Pensadores que inventaram o Brasil. \\ São Paulo: Companhia das Letras, 2013. 239 p.
}

POR

Márcio Ferreira de Souza ${ }^{1}$

$\mathrm{D}$ ez autores são contemplados por Fernando Henrique Cardoso em Pensadores que inventaram o Brasil, coletânea composta por dezoito ensaios, que combina alguns escritos do sociólogo paulista entre 1978 a 2013. Para além dos dezoito textos presentes, a referida publicação conta ainda com um posfácio assinado por José Murilo de Carvalho, no qual o historiador mineiro ressalta o que considera ser a principal virtude dos ensaios presentes na edição: o fato de surgirem "em momento histórico em que entre nós o estudo das ideias quase se limitava à busca de suas determinações estruturais, em que elas eram reduzidas a ideologias". Neste sentido, Fernando Henrique Cardoso, na avaliação de Carvalho, "revela a preocupação de buscar conteúdo e não de detectar métodos e abordagens”. (p. 298).

Uma publicação de tal porte deve ser sempre bem vinda, devido à importância dos dez autores retratados e de suas contribuições na construção de interpretações sobre o Brasil. Porém, neste caso não há tanto gosto de novidade, exceto por alguns textos específicos como o ensaio "Um crítico do Estado: Raymundo Faoro", que foi escrito exclusivamente para esta publicação, esmiuçando Os donos do poder a partir da primeira edição. Segundo FHC, nesta edição de 1958 "os fundamentos interpretativos do

\footnotetext{
Professor Adjunto do Instituto de Ciências Sociais da Universidade Federal de Uberlândia, Brasil. marcfs@uol.com.br
} 
patrimonialismo aparecem despidos de pormenores históricos" (p. 258). Na edição revista e ampliada, de 1975, Faoro acrescenta o conjunto do período getulista à sua análise sobre o patrimonialismo. A leitura crítico-interpretativa de FHC sobre Os donos do poder se concretiza pelo diálogo com sua própria produção intelectual - vide "Implantação do sistema oligárquico (Dos governos militares a Prudente-Campos Sales)", publicado em O Brasil republicano (Tomo III da História geral da civilização brasileira, de 1977, organizado por Boris Fausto) - e aponta para certos limites desta obra sob a argumentação de que "ao analisar o patrimonialismo triunfante no período republicano (...) faltaria a Raymundo Faoro esmiuçar melhor o sentido da trama entre os estamentos e as classes, o Estado e as forças do mercado. Ver a cada passo da história a repetição do mesmo modelo estamental-patrimonialista empobrece a interpretação" (p. 257).

FHC ressalta, também, que "conforme se venha dar o entrosamento entre sociedade civil e Estado, a crítica de Faoro à falta de garantias do Estado patrimonial aos direitos subjetivos dos trabalhadores e dos pobres em geral perde força como argumento para mostrar os males causados pelo patrimonialismo à racionalidade das decisões" (p.259). A despeito das diferenças interpretativas que podem ser observadas em relação às acepções de Faoro e de FHC acerca do peso da força do estamento burocrático, civil e militar no Brasil, tendo em vista que o sociólogo e ex-presidente da República, ao contrário de Faoro enfatiza mais a dinâmica transformadora das classes do que a persistência do estamento burocrático, o reconhecimento da obra analisada como referência significativa para a compreensão do Brasil é evidente.

Outros ensaios que também ganham destaque são "Joaquim Nabuco democrata", originalmente uma conferência proferida na Academia Brasileira de Letras, em março de 2010 e "Gilberto Freyre, perene", originalmente uma conferência proferida na Festa Literária Internacional de Paraty (Flip), em agosto de 2010. Estes são inéditos na forma como aparecem na presente publicação. São mais longos e consequentemente mais detalhados em suas descrições. Nabuco aparece ainda em dois curtos ensaios: "Uma síntese", resultado do discurso proferido pelo então presidente FHC, numa cerimônia comemorativa do sesquicentenário do nascimento do pensador pernambucano, em 1999, e em "Um olhar sul-americano", publicado como prefácio para a edição chilena de Balmaceda, em 2000. Freyre, por sua vez, também é tema de mais um ensaio, além do já citado: "Casa-grande E senzala, clássico", edição revista, publicada pela editora Global em 2005.

A leitura sobre Nabuco abarca o conjunto de sua obra, com referências a livros capitais como O abolicionismo (1883), Um estadista no Império (1887-1889) e Minha formação (1900) e resulta em uma interpretação focada na biografia do abolicionista, com referências à sua infância e à sua trajetória política. 0 "sentimento democrático" em Nabuco ganha destaque na interpretação de FHC, que irá apontar que 
"apesar de suas contradições, de ter sentimentos íntimos presos às tradições e a despeito de seu liberalismo não ter sido tão completo como ele pensava, não foi apenas abolicionista, mas tinha de fato uma visão democrática da sociedade" (p. 50).

0 ensaio sobre Gilberto Freyre, por sua vez, além de se debruçar sobre a importância do intérprete, reconhecido especialmente por sua "Introdução à história da sociedade patriarcal no Brasil": Casa-grande \& senzala (1933), Sobrados e mucambos (1936) e Ordem e Progresso (1959), emerge como uma espécie de mea culpa, visto que FHC, logo nas linhas iniciais, questiona: "não há motivos especiais para que seja eu quem abra nesta Flip a semana de comemorações discorrendo sobre 0 homenageado: pois não fomos nós, os chamados sociólogos da "escola paulista", Florestan Fernandes à frente, quem mais criticamos aspectos importantes da obra gilbertiana, notadamente a existência de uma democracia racial no Brasil, interpretação frequentemente atribuída a ele?" (p. 91). 0 ensaio destaca a ousadia estilística e metodológica de Freyre e procura justificar a importância da permanência de Casagrande \& senzala e Sobrados e mucambos como referências fundamentais para a compreensão do Brasil. Ainda assim FHC não se furta de críticas a Freyre apontando que este ao fazer, por exemplo, sua defesa do negro frente a preconceitos vigentes, arrisca-se em "juízos de valor" e toma como base "testemunhos insuficientes", "deixando-se levar pela imaginação" (p. 119).

Quatro dos autores contemplados tiveram importante passagem pela Universidade de São Paulo, seja como professores, a exemplos de Sérgio Buarque de Holanda (1902-1982), Antonio Candido (1918), Florestan Fernandes (1920-1995), seja como estudante, no caso de Caio Prado Jr. (1907-1990). É na USP que Fernando Henrique se formou, tendo ingressado em 1949 e construído sólida carreira como professor e sociólogo. A importância desta instituição no campo das Ciências Sociais, por obra e graça dos nomes supracitados, além de outros que aqui omitirei para não me alongar muito, decorre no que hoje se convencionou na denominação questionável de uma "Escola Paulista de Sociologia". Evidentemente que o contato de Fernando Henrique Cardoso com tais intelectuais possibilita uma leitura sobre a obra dos mesmos sob um viés muito particular e que se concretiza em forma de depoimentos reverenciadores, como os intitulados "Um ex-aluno", sobre Antonio Candido, originalmente publicado em 1992, e "A paixão pelo saber", sobre Florestan Fernandes, publicado em 1987.

Acerca de Antonio Candido destaca-se, também, o ensaio "A fome e a crença: sobre Os parceiros do Rio Bonito", originalmente publicado no livro Esboço de figura: Homenagem a Antonio Candido (Rio de Janeiro: Duas Cidades, 1979), organizado por Afonso Arinos et al. Trata-se de uma resenha detalhada sobre o estudo realizado por Antonio Candido dos meios de vida do caipira paulista, publicado em 1964. Este trabalho é citado por FHC juntamente com A organização social dos Tupinambá 
(1964), de Florestan Fernandes, como "a contribuição mais original da ciência social brasileira na época” (p. 157). E Fernando Henrique questiona o fato de que apesar de tal importância, os dois livros mencionados não tenham feito escola ainda que seus autores a fizessem através de outras obras. Da leitura de Os parceiros do Rio Bonito, FHC conclui que o essencial da contribuição desta obra se mantém: "o sentido de problema na relação entre natureza e cultura na relação entre diferentes modos de produção (0 caipira e o capitalista). A minúcia da pesquisa, sem a qual os grandes problemas correm sempre o risco de formalizarem-se e tornarem-se vazios, permitiu respostas convincentes para os problemas propostos" (p. 170).

Sobre Florestan Fernandes, o depoimento "A paixão pelo saber" aponta como objetivo "transmitir a complexidade das várias facetas da personalidade e criatividade de Florestan Fernandes" (p. 175), assim como revelar o significado do trabalho deste sociólogo paulista para a geração de FHC, bem como para as ciências sociais no Brasil. Em seu depoimento FHC revela o encontro com Florestan na Faculdade de Filosofia da USP em 1949 quando contava, então, com apenas 17 anos de idade. A figura de Florestan é exaltada por feitos relativos à sua competência profissional, com destaque para a seriedade profissional, mesclando o rigor metodológico com a competência teórica. Outro feito importante de Florestan realçado por FHC diz respeito à sua militância, seja em defesa da educação pública ou na luta pela aproximação da universidade e os trabalhadores. Mais dois ensaios sobre Florestam estão também presentes em Pensadores que inventaram o Brasil: "Florestan, cientista", publicado originalmente em 2000 como "Florestan Fernandes: a revolução burguesa no Brasil: texto introdutório", no volume Intérpretes do Brasil, organizado por Silviano Santiago e "Uma pesquisa impactante", texto de apresentação para a edição de Brancos e negros em São Paulo: ensaio sociológico sobre aspectos da formação, manifestações atuais e efeitos do preconceito de cor na sociedade paulistana (4. ed. rev. São Paulo: Global, 2008).

Alguns pequenos ensaios foram publicados em 1978, na revista Senhor Vogue. Tratam-se dos perfis de Euclides da Cunha (1866-1909), Paulo Prado (1869-1943), Sérgio Buarque de Holanda, Caio Prado Júnior e de Celso Furtado (1920-2004). FHC conviveu com este último no Chile após o golpe de 1964 e, posteriormente, em Paris entre os anos finais da década de 1960 e os iniciais de 1970. Sobre Celso Furtado ganha destaque o ensaio "A propósito de Formação econômica do Brasil", de Celso Furtado, e a Formação econômica do Brasil: edição comemorativa de 50 anos de publicação (1959-2009), publicação editada pela Ordem dos Economistas do Brasil e editora Atlas, em 2009, organizada por Francisco da Silva Coelho e Rui Guilherme Granziera.

Os ensaios publicados na revista Senhor Vogue, em 1978, como prefácios da série "Livros Indispensáveis à Compreensão do Presente", são muito curtos para abarcar em 
profundidade obras do porte de Os sertões (Euclides da Cunha, 1902), Retrato do Brasil (Paulo Prado, 1928), Raízes do Brasil (Sérgio Buarque de Holanda, 1936) e Formação do Brasil Contemporâneo (Caio Prado Jr., 1942). Sob tal aspecto permanece uma sensação de dívida ao leitor em relação às análises das referidas obras que em Pensadores que inventaram o Brasil mereciam ser mais esmiuçadas.

Pensadores que inventaram o Brasil conta ainda com um epílogo intitulado "Livros que inventaram o Brasil", uma aula magna ministrada aos alunos do Instituto Rio Branco, em maio de 1993, ocasião na qual Fernando Henrique Cardoso ocupava 0 cargo de ministro das Relações Exteriores, tendo sido publicada na revista Novos Estudos Cebrap. Aqui, a importância de Raízes do Brasil é destacada na afirmação de FHC que "do ponto de vista das ideias, Sérgio Buarque, em Raizes do Brasil, talvez tenha produzido uma revolução maior do que a feita por Gilberto Freyre" (p. 272), referindo-se ao fato de Sérgio Buarque "é um pensador radicalmente democrata, coisa que Gilberto Freyre não era. 0 pensamento de Gilberto Freyre é docemente conservador, ele concede ao povo ou ao escravo, mas não está interessado em explicar se as coisas vão mudar, por que vão mudar, até que ponto a estrutura patriarcal, em vez de ter o lado positivo ressaltado, tinha também lados que obstaculizavam as mudanças e perpetuavam uma ordem injusta" (p. 272).

Caio Prado Jr. também é citado neste ensaio, com destaque para obras como Evolução política do Brasil (1933), Formação do Brasil contemporâneo (1942), História econômica do Brasil (1945) e A revolução brasileira (1966). FHC destaca que Caio Prado Jr. "foi uma pessoa bastante diferente mentalmente" de Sérgio Buarque e de Gilberto Freyre e, sobre isso, faz uma ressalva que vale a pena transcrever: "Se Caio escreve claro, não tem a graça na elaboração das visões do Brasil de Sérgio Buarque, nem o encantamento de Gilberto Freyre. Mas, se às vezes a sofisticação dos tipos ideais de Raizes do Brasil encobre construções menos sólidas, se Gilberto idealizou muito o patriarcado e pode ser acusado de amar demais a Casa-Grande em detrimento da Senzala, em caio Prado os fundamentos da obra são visíveis e sólidos, como se fosse uma construção sem reboque" (p. 281).

Em seu conjunto Pensadores que inventaram o Brasil é uma publicação necessária, ainda que outras similares em seu propósito de revelar a gama de interpretações sobre nossa configuração nacional tenham atingido feitos que funcionem de modo mais preciso do ponto de vista didático-pedagógico. Neste sentido, a leitura de Sete lições sobre as interpretações do Brasil (Alameda, 2007), de Bernardo Ricupero ou de Um enigma chamado Brasil. 29 intérpretes e um país (Companhia das Letras, 2009), organizado por André Botelho e Lília Moritz Schwartz, são dois exemplos mais recentes de publicações que merecem destaque como introduções ao campo de conhecimento comumente denominado por pensamento social no Brasil. 0 livro de FHC não se trata necessariamente de uma introdução ao pensamento social brasileiro, 
embora possa por algum aspecto contribuir neste sentido, sobretudo em relação a alguns textos mais específicos. Alguns ensaios, porém, podem ser mais relevantes para o leitor já familiarizado com as obras dos pensadores retratados. Em particular os já citados ensaios curtos da revista Senhor Vogue, que deixam a sensação de vagueza para o leitor neófito. Eis, portanto, uma reunião de reflexões de um intelectual maduro que a despeito de um desequilíbrio qualitativo em relação aos ensaios apresentados, revela 0 quanto é ainda pertinente e instigante a discussão sobre a nossa formação e nossos modos de ser. 